\title{
Aluminum Cladding Oxidation of Prefilmed In-Pile Fueled Experiments
}

\author{
W.R. Marcum \\ Oregon State University, Department of Nuclear Engineering \& Radiation Health Physics \\ 116 Radiation Center, Corvallis, OR, 97331 \\ D.M. Wachs, A.B. Robinson, M.A. Lillo \\ Idaho National Laboratory, Nuclear Fuels \& Materials Department \\ 2525 Fremont Ave., Idaho Falls, ID, 83415
}

Corresponding Author Contact Information:

Dr. Wade R. Marcum

Department of Nuclear Engineering

and Radiation Health Physics

116 Radiation Center

Oregon State University

Corvallis OR, 97330

Phone 1 (541) 7372341

Fax 1 (541) 7370480

E-mailmarcumw@engr.orst.edu

Submitted to Journal of Nuclear Materials as a full length article

August 17, 2016

The contents of this manuscript have not been submitted elsewhere for publication, nor has this paper been submitted simultaneously for publication elsewhere.

\begin{abstract}
A series of fueled irradiation experiments were recently completed within the Advanced Test Reactor Full size plate In center flux trap Position (AFIP) and Gas Test Loop (GTL)
\end{abstract}


campaigns. The conduct of the AFIP experiments supports ongoing efforts within the global threat reduction initiative (GTRI) to qualify a new ultra-high loading density low enriched uranium-molybdenum fuel. This study details the characterization of oxide growth on the fueled AFIP experiments and cross-correlates the empirically measured oxide thickness values to existing oxide growth correlations and convective heat transfer correlations that have traditionally been utilized for such an application. This study adds new and valuable empirical data to the scientific community with respect to oxide growth measurements of highly irradiated experiments, of which there is presently very limited data. Additionally, the predicted oxide thickness values are reconstructed to produce an oxide thickness distribution across the length of each fueled experiment (a new application and presentation of information that has not previously been obtainable in open literature); the predicted distributions are compared against experimental data and in general agree well with the exception of select outliers. 


\section{INTRODUCTION}

Recently, a series of in-pile fueled experiments were irradiated in the Advanced Test Reactor (ATR). These experiments, referred to as the Advanced Test Reactor Full size plate In center flux trap Position (AFIP) configuration, were placed in the ATR for the purpose of supporting the qualification of a prototypic ultra-high loading density low enriched uraniummolybdenum alloy fuel (U-10Mo). The qualification of said fuel supports ongoing efforts within the Global Threat Reduction Initiative (GTRI) to convert all civilian Research and Test Reactors (RTRs) from highly enriched uranium to low enriched uranium fuel. The outcome of this experimental study has provided insight regarding the fuel's microstructural stability under extreme conditions to complement existing work that has been completed within the Reduced Enrichment for Research and Test Reactors (RERTR) irradiation campaigns. In addition to the fuel's microstructural state, characterization of the cladding has been performed on samples removed from the ATR. This study details the characterization of cladding oxide growth on the fueled experiments and cross-correlates the empirically measured oxide thickness values to existing oxide growth correlations and convective heat transfer correlations that have traditionally been utilized for such application. This study adds new and valuable empirical data to the scientific community with respect to oxide growth measurements of highly irradiated experiments, of which there is presently very limited data. The outcome of this study provides context toward the limitations of each respective oxide growth correlation and its partner convective heat transfer correlation. In general the correlated thickness levels match well with respect to the experimental data with the exception of a few outliers. A summary of the correlations and irradiation experiments (reference tests) that are considered herein is presented in Table 1. 


\section{(Please Insert Table 1 Here)}

\section{THEORY}

The study of metal corrosion directed toward nuclear reactor applications has become a canonical problem in recent years. Metal corrosion studies have recently centered focus on accident tolerant nuclear reactor cladding and in-core components [1-3] to expand upon the existing fuel and cladding technologies within the nuclear power industry [4]. Although there has been a resurgence of scientific interest in this area, corrosion within the RTR community has been a topic of interest since operation of the earliest reactors [5]. Traditionally, aluminum (of a variety of alloys) has been a common material for RTR cladding. The use of aluminum cladding in a RTR has many benefits including its efficient heat conductance, relatively low specific activity, low thermal neutron absorption, and ease of manufacturability. In contrast, the use of aluminum over other alloys often used as cladding (such as zirconium or stainless steel) delivers a lower melting temperature, and higher rate of corrosion (oxidation). When considering these factors, most low power RTRs need not consider the negative aspects of aluminum, however for those reactors which operate under high power densities such as the U.S. High Performance Research Reactors (HPRRs), the rate of corrosion of aluminum clad relative to that of an operational cycle has potential to impact operations and safety [6]. The oxide layer that forms between the aluminum clad and coolant acts as an insulator due to its relatively low thermal conductivity (e.g. $\sim 2.25 \mathrm{~W} / \mathrm{m}-\mathrm{K}$ [7]). Furthermore, if the Bayerite phase $\left(\alpha-\mathrm{Al}(\mathrm{OH})_{3}\right)-\mathrm{a}$ particularly 'aggressive' phase of aluminum oxide - begins to grow on the clad surface versus that of the anticipated Boehmite phase $\left(\gamma-\mathrm{AlO}(\mathrm{OH})_{3}\right)$ which is pre-filmed on in-pile aluminum 
hardware, the cladding surface has a higher likelihood of cyclic corrosion-spalling, leading to further safety related concerns [8].

\subsection{Oxide Growth}

The influence and relation of oxide growth on aluminum has been correlated to a multitude of factors, including the heat flux passing through the oxide layer, fluid water chemistry, fluid flow rates (heat removal and shear forces), radiolysis of the water in the reactor environment, starting characteristics of the prefilmed layer, and initial aluminum surface conditions. Scientists have developed empirical and semi-empirical relations which attempt to predict said growth rate while including some or all of these factors into their study. The first prominently disseminated correlation developed was by Griess et al. through a series of out-ofpile flow tests. This empirical relation was originally developed to support the safety basis for the High Flux Isotope Reactor (HFIR) [9-11], and later expanded to include characteristics which supported design features specific to the ATR [12]. In Griess' study a relation was made through use of a power law

$$
\frac{\partial x}{\partial t}=k x^{-p}
$$

where $x$ represents oxide thickness $(\mu \mathrm{m}), t$ is time $(\mathrm{hr}), k$ is the reaction constant, and $p$ is the rate-law power. For the case of Griess' study, the rate-law power was 0.28535 and reaction constant was empirically found to be

$$
k=1.2539 \times 10^{5} \exp \left(-\frac{5913}{T_{x}}\right)
$$

where $T_{x}$ is the surface temperature $(\mathrm{K})$ of the oxide at the oxide-water interface. Integrating equation (1) to time $t$ with an assumed initial oxide thickness of $x_{o}$ yields the generic solution [12] 


$$
x=\left(x_{o}^{(p+1)}+(p+1) k t\right)^{\left(\frac{1}{p+1}\right)}
$$

or

$$
x=\left(x_{o}^{1.28535}+1.28535 k t\right)^{\frac{1}{1.28535}}
$$

for the explicit form of the Griess correlation. Expanding on the work of Griess et al., Hanson developed a relation which assumed that the growth rate of the oxide layer took on an exponential relation with a constant reaction constant, leading to the correlation [5]

$$
x=60.782 t^{0.2578} \exp \left(-\frac{2412.5}{T_{x}}\right)
$$

Following the relation developed by Hanson, Kritz identified a significant influence of the reaction constant on heat flux. He utilized the originally derived relation by Griess et al. in equation (4), but developed a new rate constant relation $[13,14]$

$$
k=8.686 q^{\prime(1+p)} \exp \left(-\frac{2416.5}{T_{x}}\right)
$$

where $q^{\prime \prime}$ represents heat flux $\left(\mathrm{MW} / \mathrm{m}^{2}\right)$, and $p$ (the rate-law power) assumes the same value found by Griess et al. Following these efforts, design of the Advanced Neutron Source Reactor (ANSR) spurred the need to further expand upon the knowledge base of existing correlations. In the 1990s Pawel et al. published several reports which relate the previously developed relations to the conditions proposed for the ANSR. These relations were then tailored toward the conditions of the ANSR by changing the rate-law power to 0.351 and the reaction constant to $[15,16]$

$$
k=6.388 \times 10^{7} \exp \left(-\frac{9154}{T_{x}+1.056 q^{\prime \prime}}\right)
$$


Most recently, Kim et al. attempted to construct a more mechanistic model to predict the oxide growth rate on aluminum plates. The data utilized to acquire such results was tabulated from inpile experiments coming from the ATR. The final form of Kim et al.'s model uses the solution form of equation (3), however, the rate-law power and reaction constant are correlated differently to the study's empirical data sets such that

$$
p=0.12+9.22 \exp \left(-\frac{C_{s}}{6.82 \times 10^{-9}}\right),
$$

where $C_{s}$ is the oxide solubility $\left(\mathrm{g} / \mathrm{g} \mathrm{H}_{2} \mathrm{O}\right)$ which is dependent on fluid $\mathrm{pH}$

$$
\ln C_{s}=-\left(13.79-\frac{1211.16}{T_{x}}\right)\left(0.041 H^{2}-0.41 H-0.07\right),
$$

and $H$ represents the fluid $\mathrm{pH}$. Lastly, Kim et al. defined the reaction constant to be

$$
k=3.9 \times 10^{5} \exp \left(\frac{-6071}{T_{x}+A B \frac{q^{\prime \prime} x}{k_{x}}}\right),
$$

where $k_{x}$ is the oxide thermal conductivity $(\mathrm{W} / \mathrm{m}-\mathrm{K}), B$ is an augmentation factor identified as 0.37 by Kim et al., $A$ is an augmentation factor expressed as

$$
A=0.43+\frac{3.21}{1+\exp \left(-\frac{v_{f}-13.39}{3.60}\right)},
$$

and $v_{f}$ is the fluid superficial velocity $(\mathrm{m} / \mathrm{s})$. [7]

These five relations are the most commonly used correlations for aluminum oxide growth within the nuclear reactor community as applied toward aluminum alloys. Each was developed over a respective range of conditions and is therefore bounded by such conditions in application. A summary of the respective bounding conditions for which each correlation was developed is presented in Table 2. The experimental data presented herein was collected from within the 
ATR, which controls is $\mathrm{pH}$ at nominally 5.3. While this is slightly outside of the range of the Griess correlation, other studies have shown that influences to the oxidation rate, based on $\mathrm{pH}$ as can be seen from a pourbaix diagram for aluminum doesn't begin to occur until $\mathrm{pH}$ levels of approximately 4.6 where passivation of aluminum transitions to corrosion [17].

Note that all of these correlations were developed via empirical data collected in out-ofpile experiments, while their use and relevance has been compared against a variety of in-pile experimental samples post-development. It is known that alloys having an appreciable absorption cross-section or exposed to high gamma field experience accelerated rates of oxide growth when compared to those of out-of-pile specimens. While the magnitude of this influence has not been quantified for aluminum alloys in research reactors, it has been shown to cause a wide range of variance in the outcome of growth rate when measuring in-pile samples. Nonetheless, the correlations developed via out-of-pile experimental data detailed herein are presently used as the safety-based relations for predicting oxide growth in research reactors having aluminum clad; the use of these relations is based on the limited availability of alternate relations and the observed precedence of fuel elements having aluminum clad for which the Greiss correlation specifically has shown to conservatively over predict the oxide growth rate, as will be detailed further herein.

\section{(Please Insert Table 2 Here)}

\subsection{Heat Transfer}

All of the oxide correlations identified herein require information about the energetic state of the cladding surface (i.e. $T_{x}$ or $q^{\prime \prime}$ ). All of the experiments considered as a part of this study experience fluid velocities well within the turbulent regime; the convection of fluid heat transfer is therefore the dominant mode of heat transfer. Newton's law of cooling, 


$$
q=h a\left(T_{x}-T_{f}\right)
$$

facilitates the ability to compute such values; where $h$ is the heat transfer coefficient $\left(\mathrm{W} / \mathrm{m}^{2}-\mathrm{K}\right), a$ is the surface area $\left(\mathrm{m}^{2}\right), T_{f}$ is the bulk fluid temperature $(\mathrm{K})$, and $q$ is the thermal power $(\mathrm{W})$. The heat flux $\left(q^{\prime \prime}\right)$ is related to the thermal power through the ratio of the surface area, $a$. All values can be explicitly input into equation (12) to yield the surface temperature for a particular set of appropriate boundary conditions; however, the heat transfer coefficient carries the most uncertainty with it. There are four commonly utilized heat transfer correlations when studying oxide growth for research reactor applications; these include the Dittus-Boelter correlation [18], the Petukhov-Popov correlation [19], the Seider-Tate correlation [20], and the Hausen correlation [21]. Each relation will be considered herein to acquire a surface temperature and then applied to yield a predicted oxide layer thickness. Of these correlations the Dittus-Boelter correlation is the most commonly used heat transfer correlation. It was developed in 1930 for heat exchangers and is valid over a range $10,000<\operatorname{Re}<120,000$ and $0.7<\operatorname{Pr}<120$, where $\operatorname{Re}$ is the Reynolds number and Pr is the Prandtl number. The Dittus-Boelter correlation,

$$
\mathrm{Nu}=\frac{h k_{f}}{D}=0.023 \operatorname{Re}^{m} \operatorname{Pr}^{n}
$$

relates the Nusselt number $(\mathrm{Nu})$ to the Re and Pr through power coefficients $m=0.8$ and $n=0.4$ for heated surfaces, while $k_{f}$ is the fluid thermal conductivity and $D$ is the hydraulic diameter (m).

In contrast to the relatively simple heat transfer relation developed by Dittus and Boelter, Petukhov and Popov developed a modified form of heat transfer correlation originally developed by Petukhov to measure local heat transfer coefficient. The Petukhov-Popov correlation includes the influence if non-recoverable frictional losses within the internal flow geometry [19], 


$$
\mathrm{Nu}=\left(\frac{f}{2}\right)\left(\frac{\operatorname{Re} \operatorname{Pr}}{1.07+12.7\left(\frac{f}{2}\right)^{\frac{1}{2}}\left(\operatorname{Pr}^{\frac{2}{3}}-1\right)}\right)\left(\frac{\mu}{\mu_{x}}\right)^{0.14},
$$

where $\mu$ is the dynamic fluid viscosity evaluated at the bulk coolant temperature $\left(\mathrm{N}-\mathrm{s} / \mathrm{m}^{2}\right), \mu_{x}$ is the dynamic fluid viscosity evaluated at the surface temperature $\left(\mathrm{N}-\mathrm{s} / \mathrm{m}^{2}\right)$, and $f$ is the friction factor taken to be

$$
f=(3.64 \log (\mathrm{Re})-3.28)^{-2},
$$

by Petukhov and Popov. Petukhov and Popov recommend using their developed correlation over a range $10,000<\operatorname{Re}<5,000,000$ and $0.5<\operatorname{Pr}<2,000$.

Alternatively, the Sieder-Tate correlation can be applied in circumstances where the effects of wall viscosity are necessary to consider [20],

$$
\mathrm{Nu}=\operatorname{Re}^{0.8} \operatorname{Pr}^{\frac{1}{3}}\left(\frac{\mu}{\mu_{x}}\right)^{0.14} .
$$

Some sources recommend using the Sieder-Tate correlation over the range $\operatorname{Re}<120,000$ [22].

Lastly, the Hausen correlation was considered herein as this was the correlation utilized in development of the oxide growth correlations by Pawel $[15,16]$. Hausen's correlation also includes influence of the fluid viscosity within a confined space [21],

$$
\mathrm{Nu}=0.116\left(\operatorname{Re}^{\frac{2}{3}}-125\right) \operatorname{Pr}^{\frac{1}{3}}\left(1+\left(\frac{D}{L}\right)^{\frac{2}{3}}\right)\left(\frac{\mu}{\mu_{x}}\right)^{0.14},
$$

where $L$ is the effective length (m).

While all four of the correlations are relatively similar in general context, having a dependence on fluid properties ( $\operatorname{Pr})$ and flow rate (Re), as will be shown, they have the potential 
to significantly impact the final predicted oxide thickness. The strong sensitivity of heat transfer coefficient to oxide thickness is the basis for considering all four of these correlations herein.

\section{DESCRIPTION OF EXPERIMENTS}

Six experiments are considered herein. These six experiments consist of five AFIP geometries (AFIP-1, -2, -3, -4, and -6) and one GTL-1 geometry as identified in Table 1. The configuration of each experiment within its radiation environment has been shown in previous work to significantly impact the outcome of oxide growth, as can been inferred through the independent variables which drive the oxide growth correlations previously detailed.

All AFIP experiments were located in the center flux trap of the ATR. They each contained two fueled plates (A and B). An overview of the geometric configuration of the AFIP geometry is shown in Fig. 1. As, expected, oxide growth is correlated to each respective surface; from Fig. 1 it can be seen that there are a total of four heated surfaces (Plate A outside, Plate A inside, Plate B inside, and Plate B outside). Each fueled plate is of sufficient length $(114.3 \mathrm{~cm})$ to occupy an equivalent axial length of the ATR core, while the fueled region within the plate is altered from test to test in order to acquire the desired nuclear kinetic characteristics for a respective experiment. Further detail regarding these specific attributes is presented by Perez et al. for each respective experiment [23-27]. During this study, oxide thickness measurements and correlations will be presented for the 'Plate A outside' surface in order to maintain conciseness; however, it is worthwhile to note that all surfaces were evaluated and all yield similar trends to the surface that will be focused on.

\section{(Please Insert Figure 1 Here)}


In contrast to the AFIP geometries, the GTL-1 is significantly reduced in cross sectional area. From Fig. 2, the GTL-1 comprises four capsules (Capsule-A, -B, -C, and -D). Each of these capsules contains four fueled plates that are stacked in a two-by-two arrangement. The total length of each plate is $10.155 \mathrm{~cm}$ and the span width of the channel is $2.25 \mathrm{~cm}$. The external geometry remains congruent for all capsules, while the material composition that comprises the plates changes from plate-to-plate and capsule-to-capsule. The capsules are supported vertically by one 'spacer' located below (downstream) and two spacers located above (upstream) of them to allow for their vertical position to be centered on the axial center of the ATR core. Further detail regarding the geometric and nuclear kinetic characteristics of the GTL-1 experiment is detailed by Perez et al. [28]. During this study, oxide thickness measurements and correlations will be presented for the 'Plate 1 and 3 outside' surface in order to maintain conciseness; however, it is worthy to note that all surfaces were evaluated and all yield similar trends to the surface that will be focused on.

After the completion of irradiation, each experiment was transported to the Idaho National Laboratory Hot Fuel Examination Facility (HFEF) using the GE-2000 cask. Upon arrival, each fuel plate assembly was examined visually and photographed to identify anomalies. They were then examined using the HFEF Remote Fuel Metrology System to measure the local aluminum oxide and plate thickness distributions. The system allows probes to be maneuvered to various measurement locations over the plates, which are held in an aluminum fixture, using a bidirectional positioning system. The two dimensional positions were measured with Sony Magna Scales. The oxide measurement was performed using a Fischer Dual Scope FMP 220 model ETA3.3h eddy current probe that makes contact with the plate and measures the aluminum oxide film thickness on the plate. Measurements were taken on one face of each plate 
following a $3 \times 7$ grid. The same measurement stage was then used to determine the local plate thickness using opposing Sony Digital Scale probes with a round contact point $4.4 \mathrm{~mm}$ in diameter. The plate thickness was measured in sixteen strips down the plate and at 175 axial locations of each plate (e.g. on a $3 \mathrm{~mm} \times 3 \mathrm{~mm}$ grid over the entire plate for a total of $\sim 3000$ data points). Gamma scanning was then performed (after $\sim 100$ days of cooling) using the Precision Gamma Scanner (which fundamentally consists of a collimator, a germanium detector system, and a positioning stage) along an axial strip down the center of each fuel plate assembly. The slit size was $0.254 \mathrm{~mm} \times 1.27 \mathrm{~mm}$ and energy resolved measurements were taken every $1.27 \mathrm{~mm}$ along the axial length of the plates.

\section{(Please Insert Figure 2 Here)}

Each respective experiment (AFIPs and GTL-1) was designed so as to vary select independent variables that may influence the safety basis of the prototypic fuel. Variables of interest include (but are not limited to) factors associated with the material and fabrication such as fuel matrix material, fuel-to-cladding diffusion barrier, bonding process (e.g. roll bond [RB], friction bond [FB], hot isostatic press [HIP]); as well as design and operational characteristics including fission density, heated length, and operational flow rate (i.e. heat flux). A summary of select variables associated with this study is provided in Table 2. Discussion will be given to some potential variables within Table 2 that lead to deviations in the correlated oxide thickness for select experiments.

\section{(Please Insert Table 2 Here)}




\section{METHOD OF COMPUTATION}

In order to compute the oxide growth calculation locally, each respective plate is divided into axial and spanwise numerical nodes. The node sizes were selected to be consistent with the physical spacing associated with the experimental oxide measurements. An explicit energy balance between the fluid and the plate at each axial node was then conducted. Heat flux values used as the inputs for each plate were taken from the experiments' respective irradiation summary report [23-28]. The growth of oxide on a plate is stiffly coupled with the plate's burnup, heat flux, and fluid thermal hydraulic aspects. In order to account for the variation of heat flux that each plate experienced over an operational cycle, the irradiation time is divided into time intervals consistent with those used in the neutron physics calculation (Monte-Carlo $\mathrm{n}$ Particle $[\mathrm{MCNP}]$ generated). The average power during the time interval was then calculated and applied toward the power distribution local to the plate during that time interval.

One dimensional heat transfer perpendicular to the plate surface is assumed in the calculations. This is a conservative assumption compared to multidimensional analysis. The heat flux through the oxide layer calculated using one-dimensional analysis is greater than that calculated using multidimensional analysis because the latter allows for heat removal in all directions.

The coolant temperature along with the fuel zone of each plate was analyzed. Zero mixing between capsules was assumed for these calculations, and the plate surface temperature was quantified for the front and back of the plates via

$$
T_{f, i}=\frac{q_{i}^{\prime \prime}}{\rho c_{p} v_{f}}+T_{f, i-1},
$$


where, $\rho$ is the fluid density $\left(\mathrm{kg} / \mathrm{m}^{3}\right), c_{p}$ is the fluid specific heat $(\mathrm{J} / \mathrm{kg}-\mathrm{K})$, and $T_{f, i-1}$ is the coolant temperature $(\mathrm{K})$ at the axial location that precedes the current axial location $(i)$. Additionally, the surface temperature of the oxide layer was computed at each respective node through

$$
T_{x}=\frac{q_{x}^{\prime \prime}}{h}+T_{f, i}
$$

where $T_{x}$ is the local surface temperature of the wall. The heat transfer coefficient $(h)$ in equation (19) was then computed separately for each respective correlation considered herein via equations (13), (14), (16), and (17) in order to satisfy the energy balance and acquire the necessary local surface temperature input $\left(T_{x}\right)$ for the oxide growth correlations.

An overview the values which correlate to both geometric forms is shown in Table 4 . These respective values will be further discussed in support of down-selecting the appropriate Nusselt number correlation(s) given applicable ranges.

\section{(Please Insert Table 4 Here)}

\section{RESULTS}

As previously mentioned, each of the oxide growth correlations is driven on a Dirichlet boundary condition (surface temperature, $T_{x}$ ); therefore they are dependent upon the ability to predict the system's convective heat removal. In order to further understand the magnitude of the four heat transfer correlations they are presented for a single AFIP geometry (AFIP-1) and the GTL-1 geometry in Fig. 3. Fig. 3 presents the dimensionless axial distance along each respective experiment $(x / L)$ against the dimensionless form of the heat transfer coefficient $(\mathrm{Nu})$. In both geometries, the Dittus-Boelter correlation predicts significantly reduced heat removal as compared to the three other correlations by up to approximately 30 percent. Note that this has been observed by others in previous heat transfer studies and is generally understood to be the 
case for small channels as the Dittus-Boelter correlation includes no information associated with the deviation of fluid viscosity between the bulk temperature and that located at the wall. While the Dittus-Boelter correlation is widely used, it was originally developed for heat exchangers having larger flow channels than that observed here and therefore assumed to carry the most disparity in its ability to appropriately predict the heat removal for this particular set of geometric conditions. The remaining three correlations predict much more similar trends of heat removal across the axial distribution and are clustered in explicit magnitude more closely (largest deviation of approximately 8 percent).

\section{(Please Insert Figure 3 Here)}

While Fig. 3 provides insight toward the differences in predicted heat removal for each correlation, it does not provide context toward the correlations' ability to appropriately predict a given oxide thickness. These four heat transfer correlations were then applied toward all five of the oxide growth correlations along of the AFIP-1 and GTL-1 to compute an axial distribution of oxide thickness and compared against the experimentally measured values; Fig. 4 presents the outcome of this comparison. The computed axial distributions presented in Fig. 4 are taken at the end of cycle as these most appropriately correlate to the measured distribution values. Note from Fig. 4 that in all cases, the Hanson, Kritz, and Griess correlations significantly over predict the oxide thickness distribution, with the Kritz correlation yielding a much more pronounced distribution than all other correlations (and experimental data) along the axial length. Additionally, in contrast to that originally hypothesized by the authors, the predicted oxide growth thickness is relatively insensitive to selection of a heat transfer coefficient. This is understood after having thoroughly examined each of the oxide growth correlations and the relative sensitivity of surface temperature to the correlated oxide thickness. Inspection of each 
correlation shows that the predicted surface temperature influences the reaction constant (first order influence on oxide thickness) within the correlation; furthermore, the surface temperature is taken in the form of a ratio within the denominator of the reaction constant (order root 1). The result is a relatively insensitive temperature dependence on the overall oxide thickness as compared to other variables such as solubility, $\mathrm{pH}$, or time.

\section{(Please Insert Figure 4 Here)}

For each combination of correlated distributions presented in Fig. 4, the Kim and Pawel correlations tended to result in the most representative distributions as compared to the measured values. Specifically, the Kim correlation slightly over-predicted (conservative) the oxide thickness, while the Pawel correlation slightly under-predicted the oxide thickness. On this basis, it was determined to further examine the experimental data via the Kim and Pawel correlations. Furthermore, because each of these correlations was insensitive to the applied heat transfer coefficient, the selection of the heat transfer coefficient was made based on its intended purpose and applicability to the study's conditions. The Petukhov-Popov correlation [19] has been selected for further use on the basis that (1) it was developed to encompass the complete range of conditions that were experienced by the irradiation experiments (refer to Table 2 and Table 3), (2) it includes influence of fluid viscosity differences between the bulk fluid and the fluid at the wall (i.e. inclusion of wall shear effect for confined space), and (3) it has been shown in previous literature to yield a relatively low correlated error in contrast to some of the other correlations (i.e. Dittus-Boelter and Sieder-Tate) [18, 20].

Leveraging the Petukhov-Popov correlation to compute the thickness via the Kim and Pawel correlations, the evolution of the oxide growth is compared between the AFIP-1 and GTL1 geometries in Fig. 5. For both AFIP and GTL geometry, the Pawel correlation predicts a 
relatively gradual growth rate through the entire cycle; in contrast, the Kim correlation yields a much more rapid growth rate initially and plateaus through the remaining irradiation time. While there exists no available experimental data to compare the evolution of the oxide thickness (with exception of the measured end-of-cycle data presented herein), the computed evolution of these oxide thickness values provides valuable insights toward future safety related analysis. For example, the use of the Kim correlation results in a rapid reduction in the fluid cross sectional flow area and increased thickness of the plate may would potentially alter the computed kinetics of the experiment (or fuel) near the beginning of life, while the application of the Pawel correlation would prolongs these changes in characteristics. The rapid initial increase in oxide thickness from the Kim correlation is found to be attributed to the inclusion of solubility and $\mathrm{pH}$ contributions within the model. Through an exercise of removing these attributes from the Kim correlation, the authors observed a similar evolution in trend (not magnitude) to that of the Pawel correlation.

\section{(Please Insert Figure 5 Here)}

Further understanding the evolution of each of these two respective relations, led to the comparison of oxide growth distribution predictions to experimental results for the size experiments considered herein. Fig. 6 presents the measured axial distribution of oxide thickness at the end of cycle for each respective experiment as compared to the Kim and Pawel correlations while applying the Petukhov-Popov correlation to them. The empirical data presented in Fig. 6 is accompanied with measurement uncertainty. These uncertainty values were quantified by collected a minimum of three oxide thickness measurements using the eddy-current probe at each respective axial location. The variance of these measurements was then summed with the instrument's uncertainty via a root-mean-square approach to provide measurement 
uncertainty with one standard deviation. In general, the predicted thickness values and distributions tend to align with the experimentally measured values. The exceptions to this include AFIP-4 and AFIP-6 experiments. Both AFIP-4 and AFIP-6 experiments experienced unique outcomes in-pile that were not initially predicted. The outcome of the AFIP-4 experiment observations showed that the test plates may have exhibited in-pile conditions that could have led to oxide spalling and therefore a reduced oxide thickness. Conditions associated with the AFIP-6 experiment led to an in-pile cladding breach [29]. During post irradiation examination of the experiment, it was observed that the inlet region $(0<x / L<0.1)$ exhibited typical oxide layer characteristics, followed by a significant increase in oxide thickness that appears to be characteristic (through visual inspection) of the Bayerite phase of oxide which has been shown to lead to a significantly thicker oxide layer [8]. The exact root-cause that led to clad breach is not explicitly known, however, the AFIP-6 experiment was designed to yield a relatively high fission density as compared to other irradiation experiments creating a larger differential temperature across the aluminum oxide layer, growing it at a much faster rate than anticipated leading to spallation. Irrespective of the anomalously large oxide layer that was grown on the AFIP-6 down-stream of the inlet region, both oxide correlations clearly predicted the oxide thickness well while in the boehmite phase.

\section{(Please Insert Figure 6 Here)}

The oxide thickness predicted by each correlation is compared to that of the experimentally measured value as seen in Fig. 7. Upon initial inspection, the correlation between predicted thickness and experimentally measured thickness yields a wide scatter that leads to little confidence in the correlations' ability to predict thickness. However, considering experiments where no clad blister or breach occurred (excluding AFIP-4 and AFIP-6) the scatter 
significantly reduces. Furthermore, it is clear that while the Kim correlation deviates in prediction by a wider margin in absolute difference than the Pawel correlation overall, the Pawel correlation tends to under predict slightly in general compared to the experimental data. Therefore the Kim correlation is recommended for use when slight over prediction of oxide thickness is desired for conservative analysis.

\section{(Please Insert Figure 7 Here)}

\section{SUMMARY}

The study detailed herein considered four prevalently utilized convection heat transfer correlations to compute the surface temperature of six unique fueled irradiation experiments that have been placed in the ATR. The calculated surface temperatures were then employed to compute the oxide layer thickness using the five most prominent oxide growth correlations for research reactors that utilize various alloys of aluminum cladding. The following conclusive observations were made as a result of this work:

- The four heat transfer coefficient correlations yield widely differing values for a single experimental configuration (refer to Fig. 3), varying in values by as much as 30 percent. However, in contrast to that originally hypothesized, the thickness of oxide layer predicted was relatively insensitive to selection of a heat transfer coefficient for all five of oxide growth correlations used (refer to Fig. 4). A single heat transfer coefficient was then downselected for all following analysis. The Petukhov-Popov correlation [19] was utilized on the basis that (1) it was developed while encompassing the complete range of conditions that were experience by the irradiation experiments (refer to Table 2 and Table 3), (2) it includes influence of fluid viscosity differences between the bulk fluid and the fluid at the wall (i.e. 
inclusion of wall shear effect for confined space), and (3) it has been shown in previous literature to yield a relatively low correlated error in contrast to some of the other correlations (i.e. Dittus-Boelter and Sieder-Tate).

- The five oxide growth correlations also yielded significantly different computed values relative to one another. Of these correlations, the Kim [7] and Pawel [16] correlations consistently predicted thickness values that aligned closest to the empirically acquired data (refer to Fig. 4). Specifically, the Kim correlation tended to slightly over predict the oxide thickness, while the Pawel correlation yielded slightly under-predicted values. These two correlations were then selected (with use of the Petukhov-Popov heat transfer correlation) for further analysis of the experiments on their consistent ability to predict oxide thickness relative to the other correlations considered.

- The evolution of the oxide layer predicted by the Kim and Pawel correlations showed that the Pawel correlation tends to predict a much more gradual development of the oxide thickness, while the Kim correlation predicts a rapid increase during the initial period of experimental exposure followed by a relatively plateaued profile (refer to Fig. 5).

- In general, the Kim and Pawel correlations did well predicting the oxide thickness distribution for all experiments (refer to Fig. 6), with the exception of a few anomalous exceptions based on operational deviations during cycle (AFIP-4 and AFIP-6).

- The comparison of predicted data for all experiments shows a relatively broad deviation (refer to Fig. 7), however, neglecting the data from AFIP-4 and AFIP-6 yields a much closer fit to the experimental results (within a 50 percent deviation in all cases). 
The outcome of this study results in the recommended use of the Petukhov-Popov correlation when predicting heat transfer coefficient and applying it toward the Kim correlation when slight over prediction of oxide thickness is desired for conservative analysis. 


\section{ACKNOWLEDGEMENTS}

This work was partially supported by the U.S. Department of Energy, Office of Nuclear Materials Threat Reduction (NA-212), National Nuclear Security Administration, under DOENE Idaho Operations Office Contract DE-AC07-05ID14517. The authors would like to extend their gratitude to the reviewers of this manuscript for their insightful observations and suggestions. Their recommendations significantly improved the quality and content of this manuscript relative to its original form, and for that the authors are grateful. 


\section{NOMENCLATURE}

$a \quad$ surface area, (m2)

A Augmentation factor, equation (11)

$B \quad$ augmentation factor, (0.37)

$c_{p} \quad$ Fluid specific heat, $(\mathrm{J} / \mathrm{kg}-\mathrm{K})$

$C_{s} \quad$ Oxide solubility, $(\mathrm{g} / \mathrm{g} \mathrm{H} 2 \mathrm{O})$

D hydraulic diameter, (m)

friction factor

$h \quad$ heat transfer coefficient, $\left(\mathrm{W} / \mathrm{m}^{2}-\mathrm{K}\right)$

$H \quad$ fluid $\mathrm{pH}$

$i \quad$ current axial location

$k \quad$ Reaction constant, $\left(\mathrm{hr}^{-1}\right)$

$k_{f} \quad$ fluid thermal conductivity (W/m-K)

$k_{x} \quad$ oxide thermal conductivity, $(\mathrm{W} / \mathrm{m}-\mathrm{K})$

$L \quad$ Effective length, (m)

$\mu \quad$ Fluid dynamic viscosity evaluated at the bulk fluid temperature, $\left(\mathrm{N}-\mathrm{s} / \mathrm{m}^{2}\right)$

$\mu_{x} \quad$ Fluid dynamic viscosity evaluated at the surface temperature, $\left(\mathrm{N}-\mathrm{s} / \mathrm{m}^{2}\right)$

$\mathrm{Nu} \quad$ Nusselt number

$p \quad$ Rate-law power

Pr Prandtl number

$q \quad$ thermal power, (W)

$q^{\prime \prime} \quad$ Heat flux, $\left(\mathrm{MW} / \mathrm{m}^{2}\right)$

Re Reynolds number 
$\rho \quad$ Fluid density, $\left(\mathrm{kg} / \mathrm{m}^{3}\right)$

$t \quad$ Time, (hr)

$T_{f} \quad$ bulk fluid temperature, $(\mathrm{K})$

$T_{x} \quad$ Surface temperature, $(\mathrm{K})$

$v_{f} \quad$ fluid superficial velocity, $(\mathrm{m} / \mathrm{s})$

$x \quad$ Oxide thickness, $(\mu \mathrm{m})$

$x_{o} \quad$ Initial oxide thickness, $(\mu \mathrm{m})$ 


\section{REFERENCES}

1. Firouzdor, V., et al., Development of Yttrium Stabilized Zirconia (YSZ) Diffusion Barrier Coatings for Mitigation of Fuel-Cladding Chemical Interactions. Journal of Nuclear Materials, 2013. 438(1-3): p. 268-277.

2. Mi, H., et al., Monitoring the Oxidation of Nuclear Fuel cladding using Raman Spectroscopy. Journal of Nuclear Materials, 2014. 445(1-3): p. 7-11.

3. Bischoff, J., et al., Corrosion of Ferritic-Martensitic Steels in Steam and Supercritical Water. Journal of Nuclear Materials, 2013. 441(1-3): p. 604-611.

4. Carmack, J., et al., Overview of the U.S. DOE Accident Tolerant Fuel Development Program. 2013, Idaho National Laboratory: Idaho Falls.

5. Hanson, G.H., et al., ATR-ETR Rates of Oxide Film Formation on Aluminum Fuel Plates, in American Nuclear Society Annual Meeting. 1974, American Nuclear Society: Philadelphia, PA. p. 127-128.

6. Laboratory, I.N., Upgraded Final Safety Analysis Report for the Advanced Test Reactor. 2003, Idaho National Laboratory.

7. Kim, Y.S., et al., Oxidation of Aluminum Alloy Cladding for Research and Test Reactor Fuel. Journal of Nuclear Materials, 2008. 378: p. 220-228.

8. Shaber, E. and G. Hofman, Corrosion Minimization for Research Reactor Fuel. 2005, Idaho National Laboratory: Idaho Falls.

9. Griess, J.C., et al., Effect of Heat Flux on the Corrosion of Aluminum by Water. Part I. Experimental Equipment and Preliminary Test Results. 1960, Oak Ridge National Laboratory: Oak Ridge. 
10. Griess, J.C., et al., Effect of Heat Flux on the Corrosion of Aluminum by Water. Part II. Influence of Water Temperature, Velocity, and pH on Corrosion-Product Formation. 1961, Oak Ridge National Laboratory: Oak Ridge.

11. Griess, J.C., et al., Effect of Heat Flux on the Corrosion of Aluminum by Water. Part III. Final Report on Tests Relative to the High-Flux Isotope Reactor. 1961, Oak Ridge National Laboratory: Oak Ridge.

12. Griess, J.C., Effect of Heat Flux on the Corrosion of Aluminum by Water. Part IV. Tests Relative to the Advanced Test Reactor and Correlation with Previous Results. 1964, Oak Ridge National Laboratory: Oak Ridge.

13. Ondrojcin, R.S., Evaluation of Mark 22 Cladding. 1983, Savannah River Laboratory.

14. Aleman, S.E., Aluminum-Oxide Temperatures of the Mark VB, VE, VR, 15, and Mark 25 Assemblies. 1984, Savannah River Laboratory.

15. Pawel, R.E., On the Kinetics of the Aluminum Water Reactor During Exposure in HighHeat Flux Test Loops. 1988, Oak Ridge National Laboratory: Oak Ridge.

16. Pawel, R.E., et al., The Development of a Preliminary Correlation of Data on Oxide Growth on 6061 Alunimum under ANS Thermal-Hydraulic Conditions. 1990, Oak Ridge National Laboratory: Oak Ridge.

17. Sukiman, N.L., et al., Durability and Corrosion of Aluminum and Its Alloys: Overviews, Property Space, Techniques and Developments, in Aluminum Alloys - New Trends in Fabrication and Applications, Z. Ahmad, Editor. 2012, InTech.

18. Dittus, F.W. and L.M.K. Boelter, Heat Transfer in Turbulent Pipe and Channel Flow. Publications on Engineering, University of California, Berkeley, 1930. 2: p. 443-461. 
19. Petukhov, B.S. and V.N. Popov, Theoretical Calculation of Heat Exchange and Friction Resistance in Turbulent Flow in Tubes of an incompressible Fluid with Variable Physical Properties. High Temperature, 1963. 1(2): p. 69-83.

20. Sieder, E.N. and G.E. Tate, Heat Transfer and Pressure Drop of Liquids in Tubes. Industrial \& Engineering Chemistry, 1936. 28: p. 1429-1435.

21. Hausen, H., New Equations for Heat Transfer at Free and Forced Fluid Flow (Neue Gleichungen Für den Wärmeübertragung bei freier oder erzwungener Strömung). Allgemeine Wärmetechnik, 1959. 9(45): p. 75-79.

22. Bejan, A., Convection Heat Transfer. Fourth ed. 2013: Wiley Press.

23. Perez, D.M., et al., AFIP-1 Irradiation Summary Report. 2011, Idaho National Laboratory: Idaho Falls.

24. Perez, D.M., et al., AFIP-2 Irradiation Summary Report. 2011, Idaho National Laboratory: Idaho Falls.

25. Perez, D.M., et al., AFIP-3 Irradiation Summary Report. 2011, Idaho National Laboratory: Idaho Falls.

26. Perez, D.M., et al., AFIP-6 Irradiation Summary Report. 2011, Idaho National Laboratory: Idaho Falls.

27. Perez, D.M., et al., AFIP-4 Irradiation Summary Report. 2012, Idaho National Laboratory: Idaho Falls.

28. Perez, D.M., et al., GTL-1 Irradiation Summary Report. 2012, Idaho National Laboratory: Idaho Falls.

29. Wachs, D.M., A.B. Robinson, and P. Medvedev, AFIP-6 Breach Assessment Report. 2011, Idaho National Laboratory: Idaho Falls. 
30. Chang, G.S. and M.A. Lillo, Detailed Fission Power 2D-Mapping of AFIP-2 Experiment in ATR CFT Position. 2008, Idaho National Laboratory: Idaho Falls.

31. Kim, Y.S., et al., Prediction Model for Oxide Thickness on Aluminum Alloy Cladding During Irradiation, in International Meeting on Reduced Enrichment for Research and Test Reactors. 2003: Chicago, IL, USA. p. 1-11.

32. Ambrosek, R.G., RELAP Analysis for AFIP-2 Flow Resistor. 2008, Idaho National Laboratory: Idaho Falls.

33. Wachs, D.M., Hydraulic Testing of The AFIP Irradiation Vehicle for the ATR Center Flux Trap Position. 2007, Idaho National Laboratory: Idaho Falls. 
Table 1. New empirical data irradiation experiment, heat transfer, and oxide growth correlations

\begin{tabular}{|lr|lr|lr|}
\hline \multicolumn{2}{|c|}{ Irradiation experiment } & \multicolumn{2}{c|}{ Heat Transfer } & \multicolumn{2}{c|}{ Oxide Growth } \\
\hline Reference Test & Reference & Correlation & Reference & Correlation & Reference \\
\hline AFIP-1 & {$[23]$} & Dittus-Boelter & {$[18]$} & Griess & {$[9-12]$} \\
AFIP-2 & {$[24,30]$} & Petukhov-Popov & {$[19]$} & Hanson & {$[5]$} \\
AFIP-3 & {$[25]$} & Sieder-Tate & {$[20]$} & Kritz & {$[13,14]$} \\
AFIP-4 & {$[27]$} & Hausen & {$[21]$} & Pawel & {$[15,16]$} \\
AFIP-6 & {$[26]$} & & & Kim & {$[7,31]$} \\
GTL & {$[28]$} & & & & \\
\hline
\end{tabular}


Table 2. Summary of conditions over which each correlation was developed

\begin{tabular}{|l|c|c|c|c|c|c|c|}
\hline Correlation & $\mathrm{pH}$ & $\begin{array}{c}\text { Coolant } \\
\text { Temperature } \\
\left({ }^{\circ} \mathrm{C}\right)\end{array}$ & $\begin{array}{c}\text { Surface } \\
\text { Temperature } \\
\left({ }^{\circ} \mathrm{C}\right)\end{array}$ & $\begin{array}{c}\text { Coolant } \\
\text { Velocity } \\
(\mathrm{m} / \mathrm{s})\end{array}$ & $\begin{array}{c}\text { Heat } \\
\left(\mathrm{MW} / \mathrm{m}^{2}\right)\end{array}$ & $\begin{array}{c}\text { Duration } \\
(\text { days })\end{array}$ & $\begin{array}{c}\text { Aluminum } \\
\text { Alloy }\end{array}$ \\
\hline Griess & $5.7-7.0$ & $54-121$ & $121-204$ & $7.6-15.2$ & $3.2-6.3$ & $10-17$ & $\begin{array}{c}\text { AA-6061 } \\
\text { AA-1100 } \\
\text { X-8001 }\end{array}$ \\
\hline Hanson & 5.0 & - & $79.4-121$ & 13.7 & $4-5$ & $9.2-47.9$ & AA-6061 \\
\hline Kritz & 5.0 & - & - & - & $2.2(\max )$ & - & AA-6061 \\
\hline Pawel & $4.5-6.0$ & $39-99$ & $95-208$ & $9-28$ & $5-20$ & $1-35$ & $\begin{array}{c}\text { AA-60601 } \\
\text { AA-1100 }\end{array}$ \\
\hline Kim & $5.1-7.0$ & $25-300$ & $25-300$ & $3-28$ & $2.2(\max )$ & - & AA-6061 \\
\hline
\end{tabular}


Table 3: Summary of experiment plate fabrication and in-pile conditions

\begin{tabular}{|c|c|c|c|c|c|c|c|c|c|c|c|c|c|c|c|c|c|}
\hline \multicolumn{11}{|c|}{ Plate Fabrication Conditions } & \multicolumn{7}{|c|}{ In-Pile Conditions } \\
\hline \multicolumn{2}{|c|}{ Reference Test } & \multirow{3}{*}{$\begin{array}{l}\text { Plate A } \\
\text { Blank }\end{array}$} & \multirow{3}{*}{\begin{tabular}{|c|} 
Plate B \\
$1 \mathrm{~T} 2$ \\
$1 \mathrm{~B} 5$ \\
\end{tabular}} & \multirow{3}{*}{$\begin{array}{c}\text { Fuel } \\
\text { U-7Mo }\end{array}$} & \multirow{3}{*}{$\begin{array}{c}\text { Matrix } \\
\text { Al-2Si } \\
\text { Al-4043 }\end{array}$} & \multirow{3}{*}{$\begin{array}{c}\text { Diffusion Barrier } \\
\text { None }\end{array}$} & \multirow{3}{*}{$\begin{array}{l}\text { Cladding } \\
\text { Al-6061 }\end{array}$} & \multicolumn{2}{|c|}{ Fabrication Process } & \multirow{3}{*}{$\begin{array}{c}\begin{array}{c}\text { Preconditioned } \\
\text { Oxide Coating }\end{array} \\
4 \mathrm{hr} @ 185 \mathrm{C} \text { in DI } \\
\text { water } \\
\text { (pH } 4.8-9.0)\end{array}$} & \multirow{3}{*}{$\begin{array}{c}\mathrm{pH} \\
(\#) \\
4.9-5.1\end{array}$} & \multirow{3}{*}{$\begin{array}{c}\begin{array}{c}\text { Coolant } \\
\text { Temperature } \\
\left({ }^{\circ} \mathrm{C}\right)\end{array} \\
52.0 \text { (inlet) } \\
61.0 \text { (outlet) } \\
55.3 \text { (avg) }\end{array}$} & \multirow{3}{*}{$\begin{array}{c}\begin{array}{c}\text { Surface } \\
\text { Temperature } \\
\left({ }^{\circ} \mathrm{C}\right)\end{array} \\
71.0(\min ) \\
116.0(\max ) \\
88.1 \text { (avg) }\end{array}$} & $\begin{array}{l}\text { Coolant } \\
\text { Velocity } \\
(\mathrm{m} / \mathrm{s})[32,\end{array}$ & \multicolumn{2}{|c|}{ Heat Flux $\left(\mathrm{MW} / \mathrm{m}^{2}\right)$} & \multirow{3}{*}{$\begin{array}{c}\text { Duration } \\
3 \text { cycles } \\
158.2 \mathrm{EFPD}\end{array}$} \\
\hline \multirow{2}{*}{ AFIP-1 } & Top & & & & & & & \multirow{2}{*}{\multicolumn{2}{|c|}{$\mathrm{RB}$}} & & & & & 1036 & \multirow{2}{*}{\multicolumn{2}{|c|}{$\begin{array}{l}0.89(\min ) \\
3.26(\max ) \\
1.73(\operatorname{avg})\end{array}$}} & \\
\hline & Bottom & & & & & & & & & & & & & 10.36 & & & \\
\hline \multirow{2}{*}{ AFIP-2 } & Top & $2 \mathrm{TT}$ & BT-Dum & \multirow{2}{*}{ U-10Mo } & \multirow{2}{*}{$\begin{array}{c}\text { none } \\
\text { (monolithic) }\end{array}$} & Thermal Spray Si & \multirow{2}{*}{ Al-6061 } & \multirow{2}{*}{\multicolumn{2}{|c|}{ FB }} & \multirow{2}{*}{$\begin{array}{c}4 \mathrm{hr} @ 185 \mathrm{C} \text { in DI } \\
\text { water } \\
(\mathrm{pH} 4.8-9.0)\end{array}$} & \multirow{2}{*}{$4.9-5.1$} & \multirow{2}{*}{$\begin{array}{c}52.0 \text { (inlet) } \\
62.0 \text { (outlet) } \\
55.9 \text { (avg) }\end{array}$} & \multirow{2}{*}{$\begin{array}{c}73.0(\min ) \\
121.0(\max ) \\
93.4(\text { avg })\end{array}$} & \multirow{2}{*}{10.36} & \multirow{2}{*}{\multicolumn{2}{|c|}{$\begin{array}{l}1.03(\min ) \\
3.59(\mathrm{max}) \\
2.00(\mathrm{avg})\end{array}$}} & 3 cycles \\
\hline & Bottom & $2 \mathrm{BZ}$ & BB-Dum & & & $\mathrm{Zr}$ & & & & & & & & & & & 132.4 EFPDs \\
\hline 4 & Top & $3 \mathrm{TT}$ & D1 & It & none & Thermal Spray Si & esere & & & $4 \mathrm{hr} @ 185 \mathrm{C}$ in DI & $40-1$ & 52.0 (inlet) & $75.0(\mathrm{~min})$ & 1006 & 1.16 & nin) & 2 cycles \\
\hline AFIP-3 & Bottom & $3 \mathrm{BZ}$ & Blank & U-10MO & (monolithic) & $\mathrm{Zr}$ & Al-6061 & $\mathrm{H}_{\mathrm{S}}$ & & $\begin{array}{c}\text { water } \\
(\mathrm{pH} 4.8-9.0)\end{array}$ & $4.9-5.1$ & $\begin{array}{c}62.0 \text { (outlet) } \\
55.9 \text { (avg) }\end{array}$ & $\begin{array}{c}120.0 \text { (max) } \\
94.7 \text { (avg) }\end{array}$ & 10.36 & $\begin{array}{l}3.51 \\
2.0 \\
\end{array}$ & $\begin{array}{l}\operatorname{nax} \text { (avg) } \\
\text { avg }\end{array}$ & 101 EFPDs \\
\hline & & L1B31Z & L1H34Z & & & & & (Plate A) & (Plate B) & & & & & & (Plate A) & (Plate B) & \\
\hline & Top & L1B33Z & L1H35Z & & & & & & & $4 \mathrm{hr} @ 185 \mathrm{C}$ in DI & & 52.0 (inlet) & $73.0(\min )$ & & & & \\
\hline AFIP-4 & & \begin{tabular}{|l|} 
L1B32Z \\
L1B51Z
\end{tabular} & $\begin{array}{l}\text { L1H36Z } \\
\text { L1H37Z }\end{array}$ & U-10Mo & $\begin{array}{l}\text { none } \\
\text { (monolithic) }\end{array}$ & $\mathrm{Zr}$ & Al-6061 & FB & HIP & water & $4.9-5.1$ & 70.0 (outlet) & $118.0(\max )$ & 10.36 & $\begin{array}{l}1.06 \text { (min) } \\
3.19 \text { (max) }\end{array}$ & $\begin{array}{l}1.04(\min ) \\
3.14(\max )\end{array}$ & 2 cycles \\
\hline & Bottom & \begin{tabular}{|l} 
L1B52Z \\
L1B53Z \\
\end{tabular} & $\begin{array}{l}\text { L1H38Z } \\
\text { L1H39Z }\end{array}$ & & & & & & & $(\mathrm{pH} 4.8-9.0)$ & & 55.5 (avg) & 94.6 (avg) & & 1.96 (avg) & 1.92 (avg) & \\
\hline AFIP-6 & & $6 \mathrm{ZH}-1$ & $6 \mathrm{ZH}-2$ & U-10Mo & $\begin{array}{c}\text { none } \\
\text { (monolithic) }\end{array}$ & $\mathrm{Zr}$ & Al-6061 & $\mathrm{H}$ & & $\begin{array}{c}18 \mathrm{hr} @ 185 \mathrm{C} \text { in DI } \\
\text { water } \\
(\mathrm{pH} 5.0-9.0)\end{array}$ & $4.9-5.1$ & $\begin{array}{c}52.0 \text { (inlet) } \\
72.0 \text { (outlet) } \\
61.3 \text { (avg) }\end{array}$ & $\begin{array}{l}126.0(\min ) \\
156.0(\max ) \\
140.4(\operatorname{avg})\end{array}$ & 10.36 & $\begin{array}{c}\text { (Plate A) } \\
4.14 \text { (min) } \\
5.25(\max ) \\
4.64 \text { (avg) }\end{array}$ & $\begin{array}{c}\text { (Plate B) } \\
4.03 \text { (min) } \\
5.08(\max ) \\
4.51 \text { (avg) }\end{array}$ & $\begin{array}{c}1 \text { cycle } \\
39.2 \text { EFPDs }\end{array}$ \\
\hline & & US06C & US15DM & & & & & & & & & & & & (Plate A) & (Plate B) & \\
\hline & & US03HS & US11GS & & & & & & & & & & & & & & \\
\hline & & US04GS & UN01FS & & & & & & & $18 \mathrm{hr} @ 185 \mathrm{C}$ in DI & & & & & $3.41(\mathrm{~min})$ & $3.42(\mathrm{~min})$ & \\
\hline GTL-1 & & US2FS & UA01FS & $\mathrm{U}_{1} \mathrm{Si}_{2}$ & Al-6061 & None & Al-6061 & $\mathrm{N}$ & & water & $48-60$ & $\begin{array}{l}54 \text { (iniet) } \\
81 \text { (outlet) }\end{array}$ & $\begin{array}{l}99.0(\mathrm{~min}) \\
148.0(\mathrm{max})\end{array}$ & 1460 & $6.56(\max )$ & $6.58(\max )$ & 1 cycle \\
\hline GIL-1 & & \begin{tabular}{|l|} 
US07FS \\
\end{tabular} & US16DM & $\mathrm{U}_{3} \mathrm{~S}_{2}$ & & & & & & $(\mathrm{pH} 8.0 \pm 0.2)$ & & 64.97 (avg) & $121 . .2$ (avg) & & 4.55 (avg) & 4.50 (avg) & 48.9 EFPDs \\
\hline & & \begin{tabular}{|l|} 
US08CS \\
US09GS
\end{tabular} & $\begin{array}{l}\text { US14DS } \\
\text { UN03ES }\end{array}$ & & & & & & & & & & & & & & \\
\hline & & US13GS & US17GM & & & & & & & & & & & & & & \\
\hline
\end{tabular}


Table 4: AFIP and GTL conditions used to determine appropriate Nusselt number correlation

\begin{tabular}{|l|c|c|}
\hline \multirow{2}{*}{\multicolumn{1}{|c|}{ Parameter }} & \multicolumn{2}{c|}{ Value } \\
\cline { 2 - 3 } & AFIP & GTL-1 \\
\hline Channel width [cm] & 4.85 & 2.25 \\
\hline Channel gap [cm] & 0.51 & 0.38 \\
\hline Hydrodynamic length [cm] & 114.3 & 81.24 \\
\hline Heated length [cm] & 52.39 & 38.1 \\
\hline Flow area [cm $\left.{ }^{2}\right]$ & 2.474 & 0.855 \\
\hline Wetted perimeter $[\mathrm{cm}]$ & 10.72 & 5.26 \\
\hline Hydraulic diameter [cm] & 0.92 & 0.65 \\
\hline Inlet temperature $\left[{ }^{\circ} \mathrm{C}\right]$ & 52 & 52 \\
\hline Coolant velocity $[\mathrm{m} / \mathrm{sec}]$ & 10.36 & 14.56 \\
\hline Reynolds number range & $180,000-210,000$ & $177,000-270,000$ \\
\hline Prandtl number range & $2.90-3.50$ & $2.10-3.30$ \\
\hline Mass flow rate $[\mathrm{kg} / \mathrm{sec}]$ & 2.52 & 1.20 \\
\hline Surface heat flux $\left[\mathrm{W} / \mathrm{cm}^{2}\right]$ & $90-530$ & $340-660$ \\
\hline
\end{tabular}




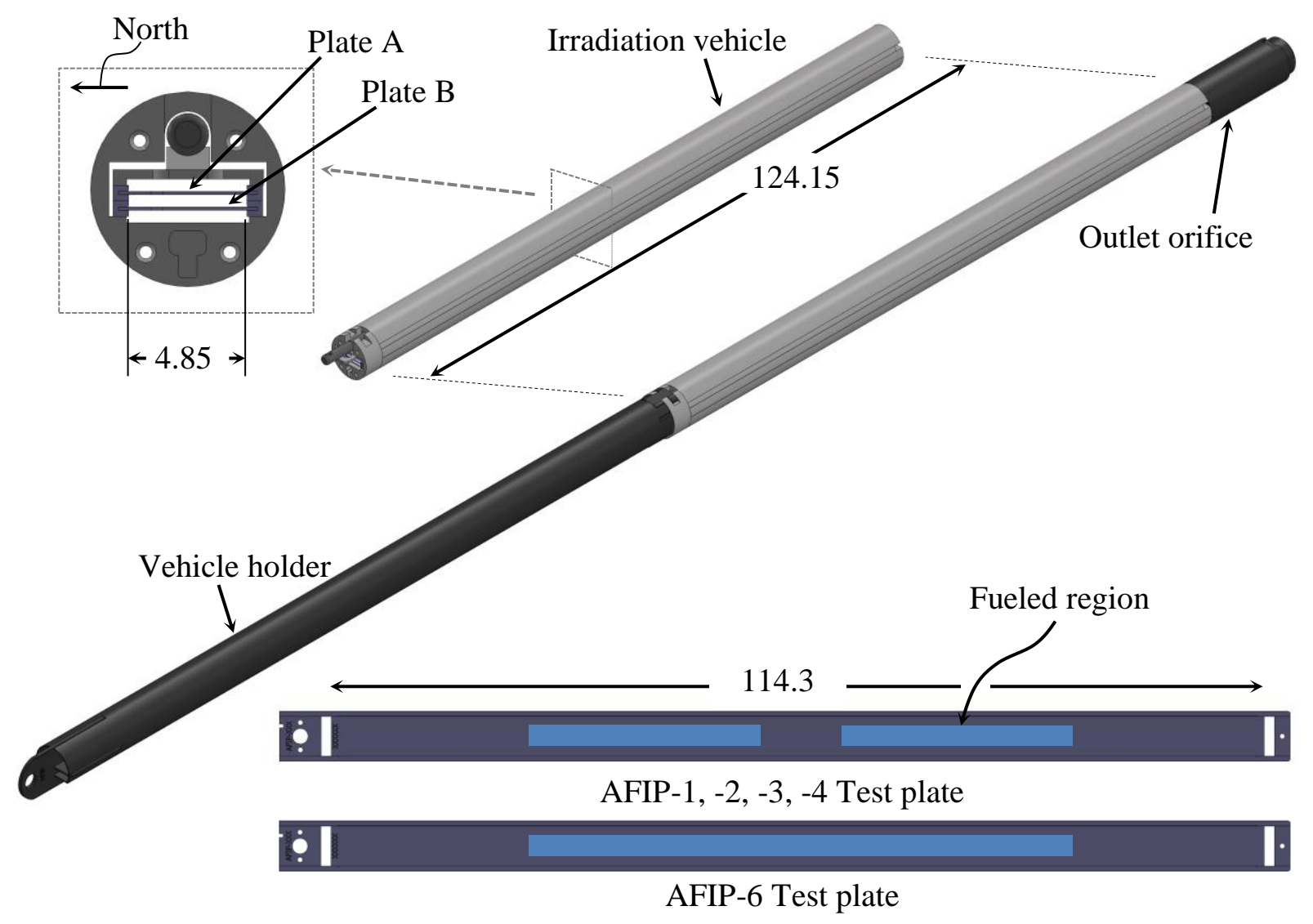

Fig. 1. Physical configuration of AFIP irradiation experiments, dimensions in $\mathrm{cm}$ 


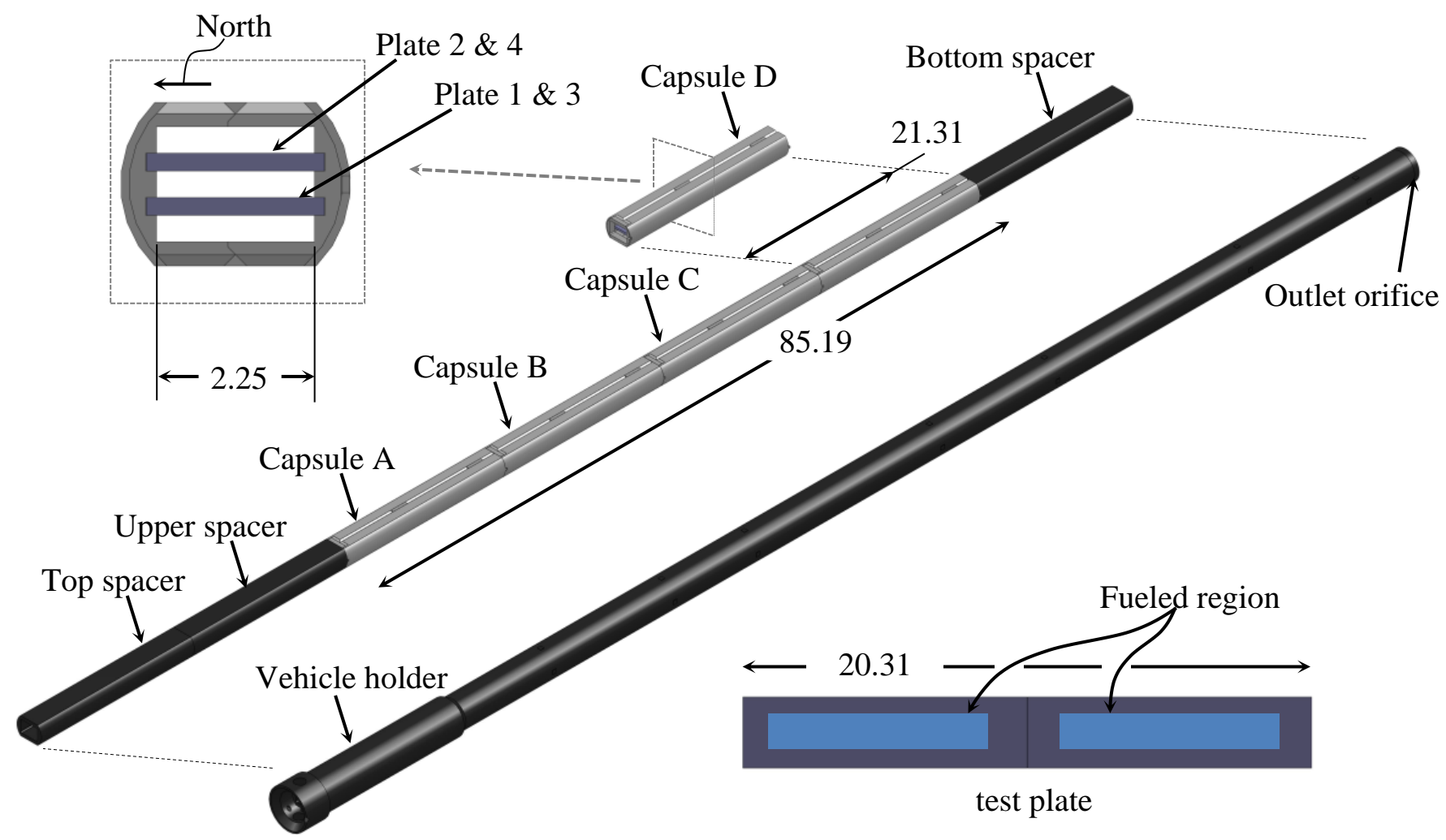

Fig. 2. Physical configuration of GTL-1 irradiation experiment, dimensions in $\mathrm{cm}$ 


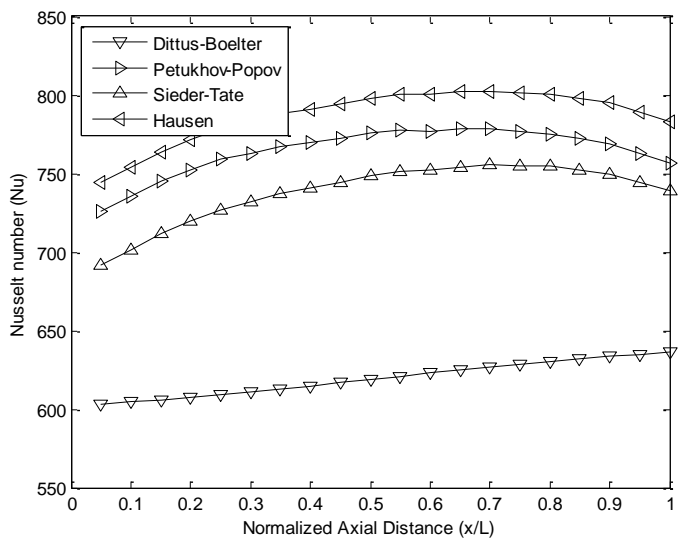

(a)

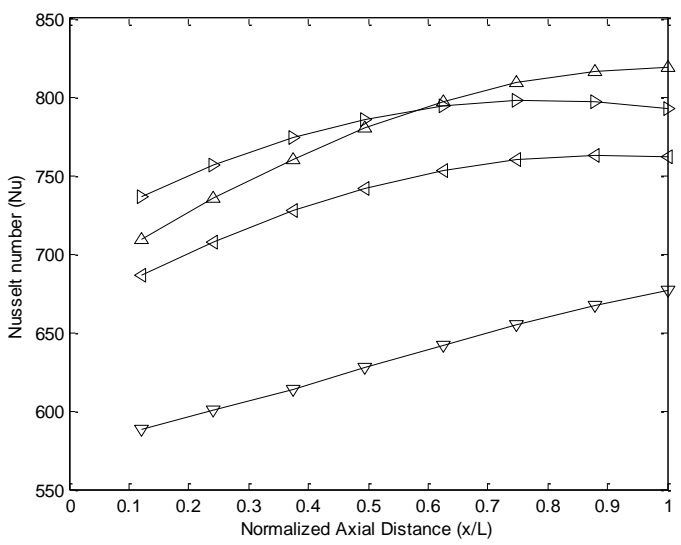

(b)

Fig. 3. Axial distribution of Nusselt number for AFIP-1 (a) and GTL-1 (b) 


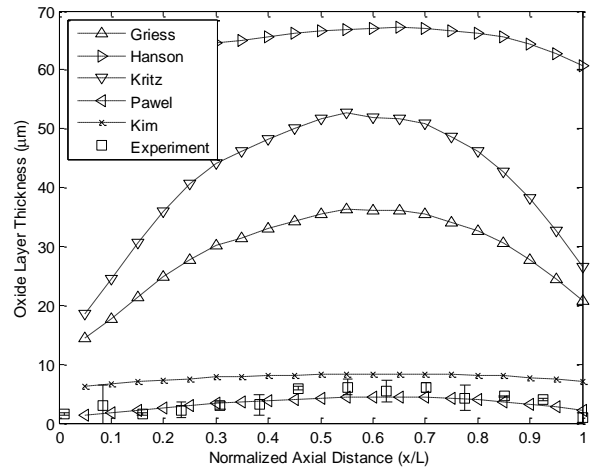

(a)

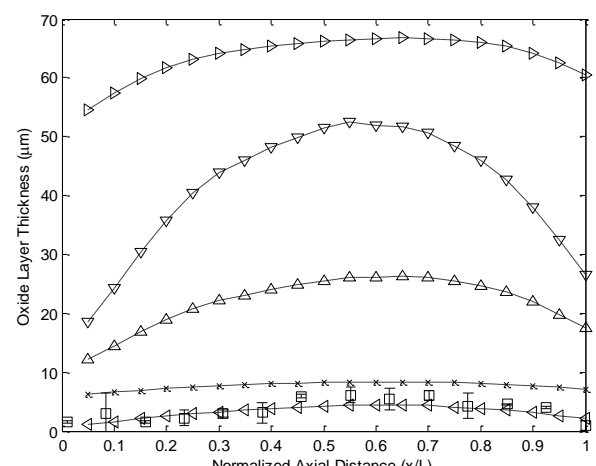

(c)

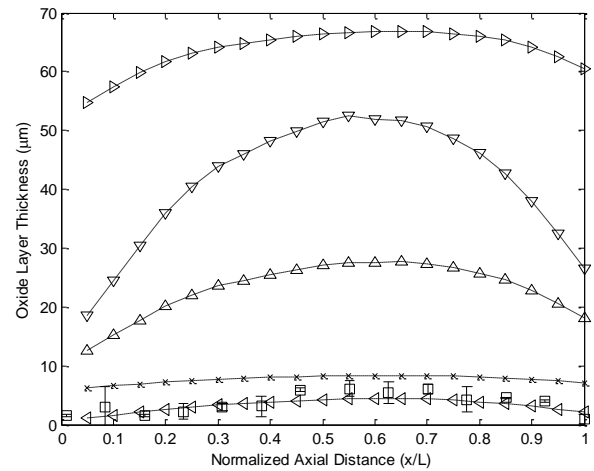

(e)

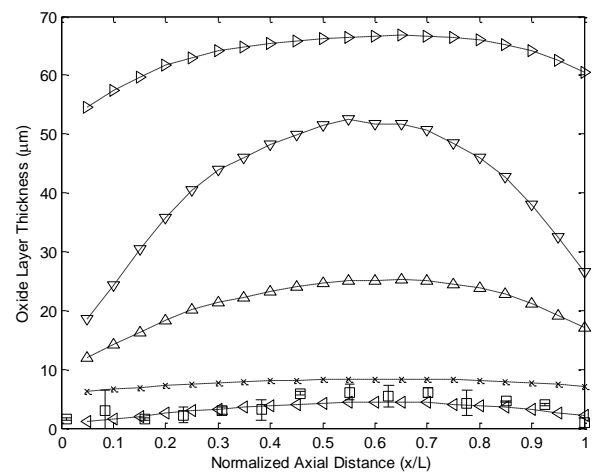

(g)

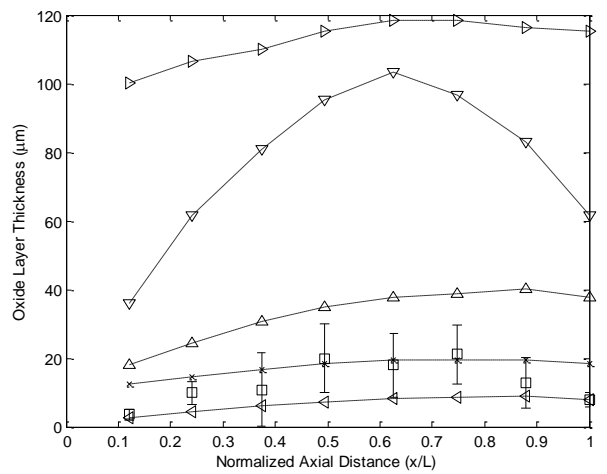

(b)

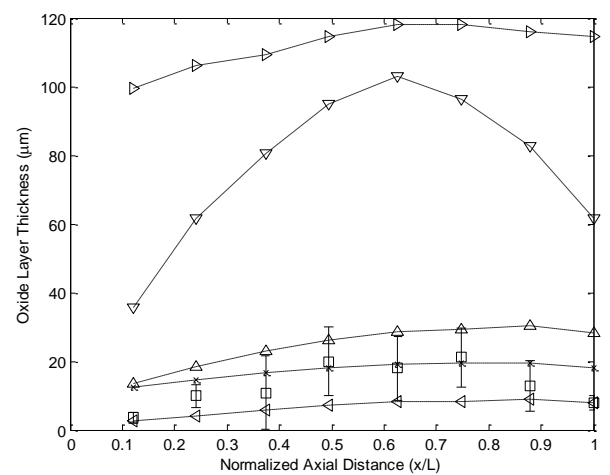

(d)

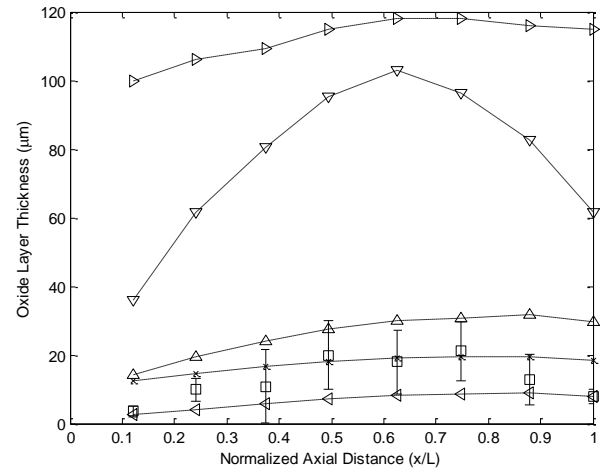

(f)

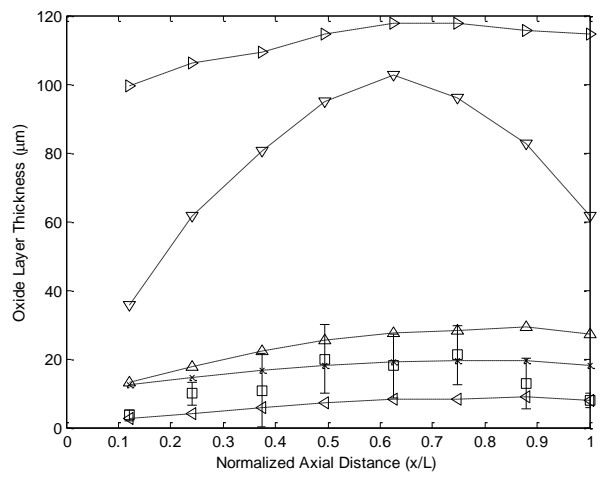

(h)

Fig. 4. Axial distribution of oxide layer for AFIP-1 (left column) and GTL-1 (right column) using the DittusBoelter (a-b), Petukhov-Popov (c-d), Sieder-Tate (e-f), and Hausen (g-h) correlations. 


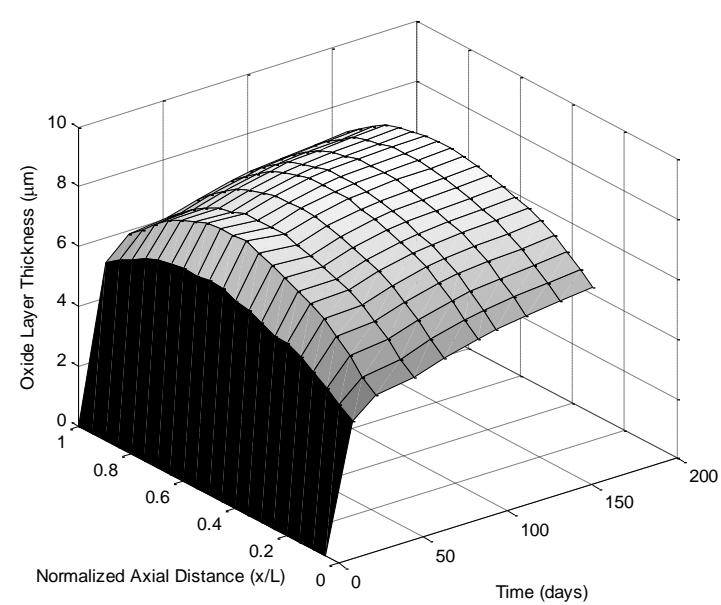

(a)

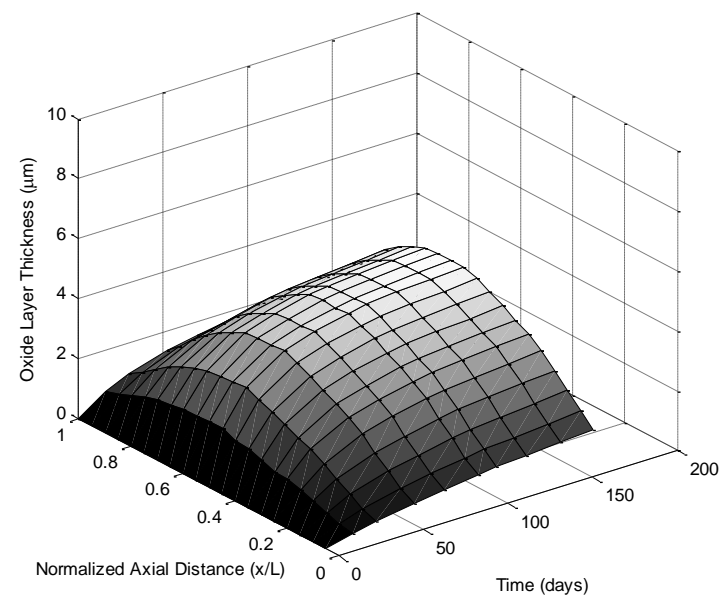

(c)

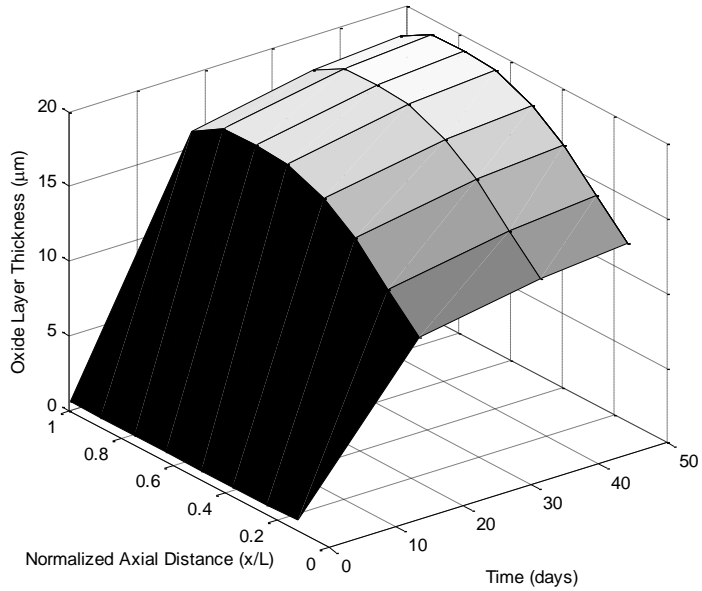

(b)

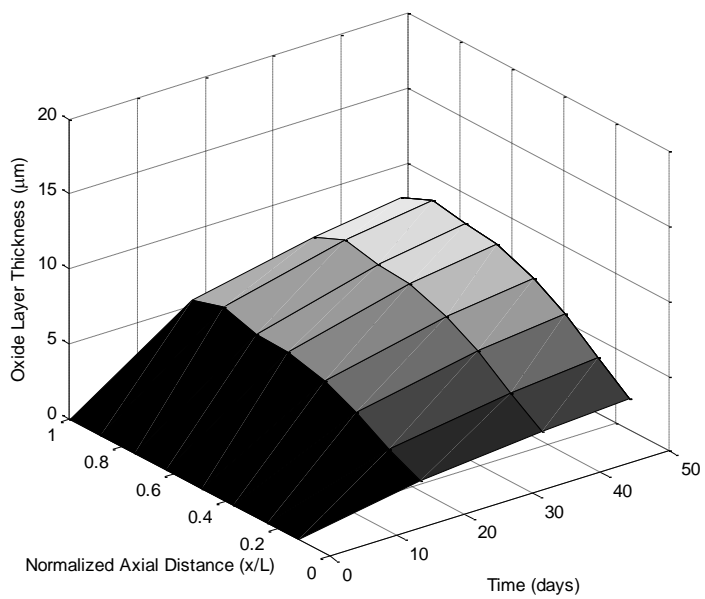

(d)

Fig. 5. Evolution of oxide growth distribution for AFIP-1 (left column) and GTL-1 (right column) using the Kim (a-b) and Pawel (c-d) correlation 


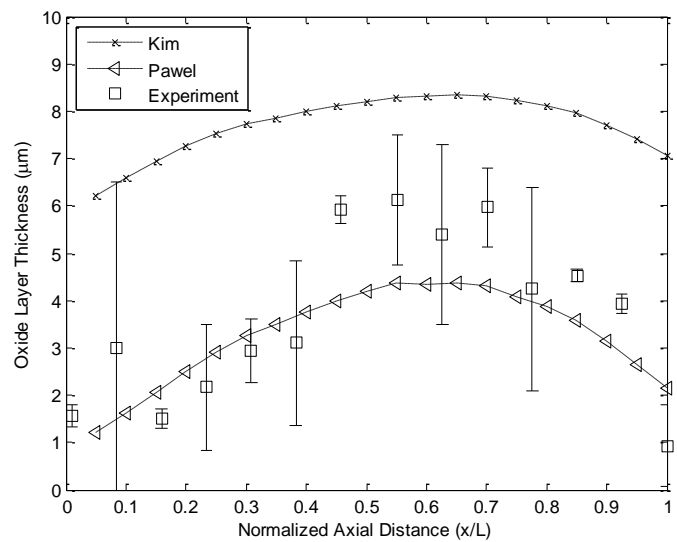

(a)

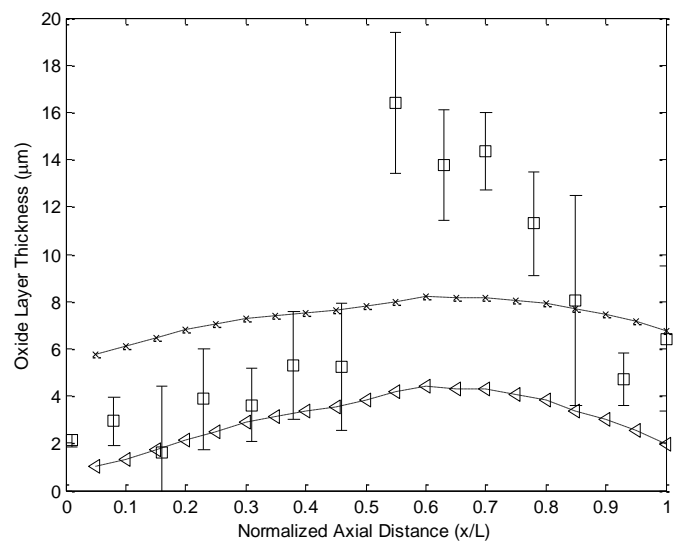

(c)

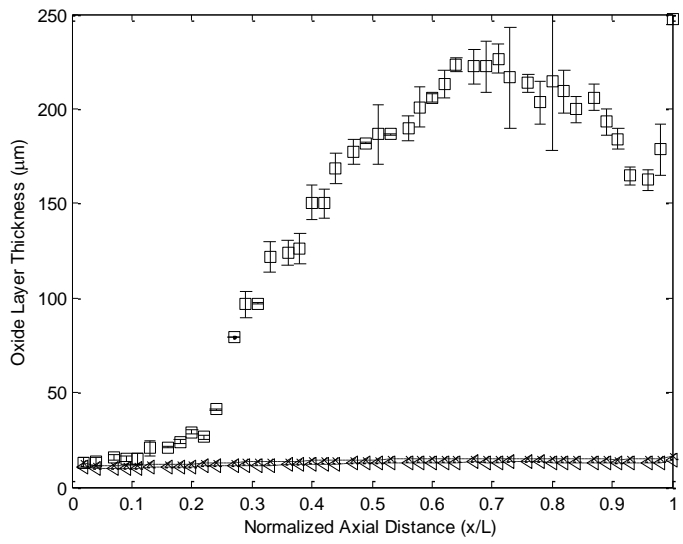

(e)

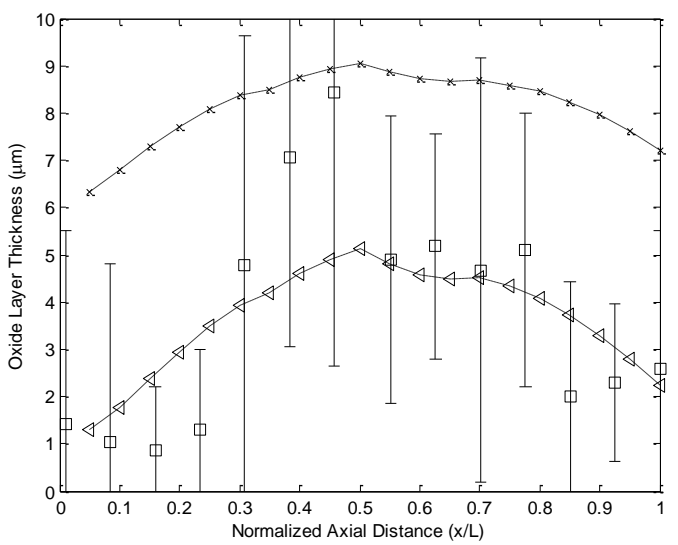

(b)

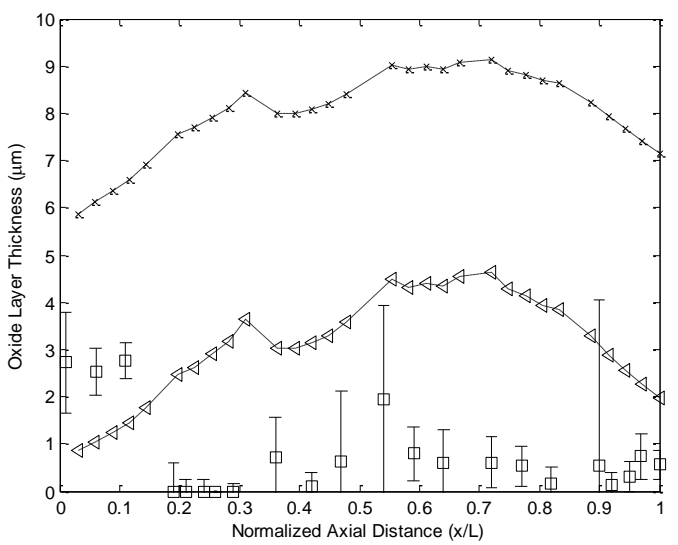

(d)

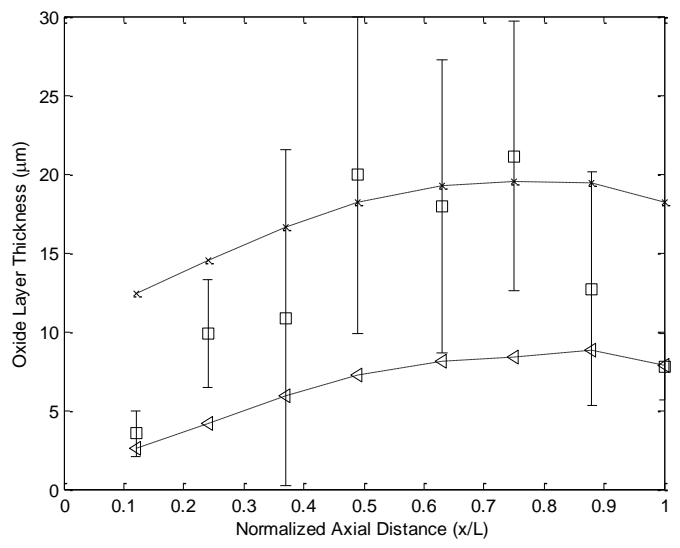

(f)

Fig. 6. Axial oxide layer thickness of AFIP-1 (a), AFIP-2 (b), AFIP-3 (c), AFIP-4 (d), AFIP-6 (e), and GTL-1 


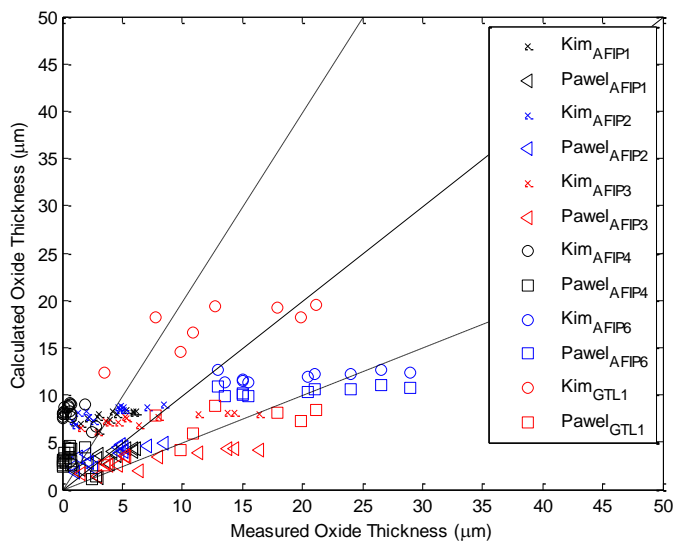

(a)

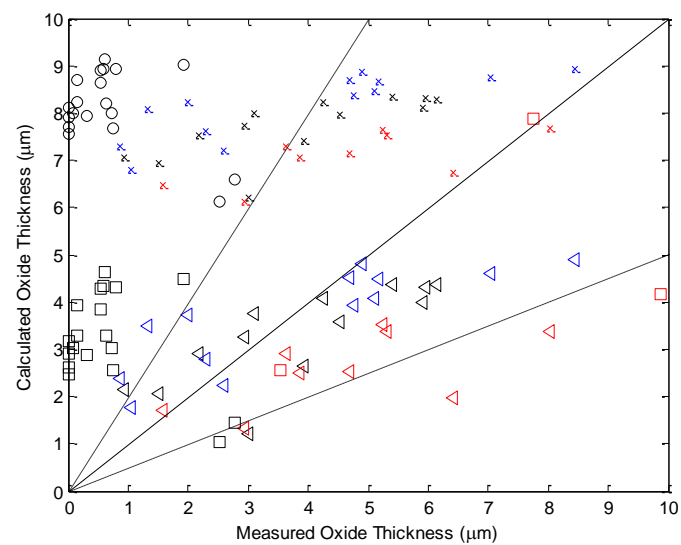

(b)

Fig. 7. Comparison of Kim and Pawel correlated predictions to measured data of all data (a) and small oxide thickness (b) 